$\mathrm{NE}$ as a primary efficacy endpoint in clinical trials or as a marker of inflammation within the clinic has been hampered by the lack of a robust and simple to use assay. ProteaseTag ${ }^{\mathrm{TM}}$ Active NE Immunoassay specifically measures only active NE in clinical samples, is quick and easy to use $(<3 \mathrm{~h})$ and has no dependency on a kinetic readout. ProteaseTag ${ }^{\mathrm{TM}}$ technology is currently being transferred to a lateral flow device for use at Point of Care.

\section{P103 INHIBITION OF ASTHMA-RELATED IMMUNOLOGICAL RESPONSES BY CULTURED EPITHELIAL CELL LINES}

W Sargent, L Stoeger, I Pavord, TJ Powell. Respiratory Medicine Unit, NDM, University of Oxford, Oxford, UK

\subsection{6/thoraxjnl-2015-207770.240}

Background Previous studies have shown that constitutive and IgE-mediated histamine production by human lung mast cells is inhibited by a transferable factor produced by the airway epithelium. We have tested the hypothesis that a similar interaction exists between epithelial cell and mast cell lines. We have also investigated the effect of co-culture of epithelial cell lines and $\mathrm{T}_{\mathrm{H}} 2$ cells on interleukin (IL)-13 production.

Methods A549 or BEAS-2B cells were grown to confluence overnight. Media was removed and LAD2, HMC1.2 or humanderived ex-vivo T-cells added for $16 \mathrm{~h}$. For transwell experiments epithelial cells were added to a 24 -well plate, replaced with fresh media after $16 \mathrm{~h}$ and mast cells media added to the insert, maintaining the mast cell/epithelium/volume ratio. Wells, and transwell insert media, were then centrifuged, supernatants harvested and mediator release quantified by histamine or IL-13 ELISA.

Results Neither mast cell line consistently produced histamine in response to $\operatorname{IgE}$ and anti-IgE. Flow cytometry suggested that this was due to absence of the high-affinity $\operatorname{IgE}$ receptor $\mathrm{Fc} \in \mathrm{R} 1$. Constitutive histamine production by HMC1.2 was reduced from $191 \pm 13 \mathrm{ng} / 10^{6}$ cells by $60.9 \%$ (95\% CI 54.1, 67.8; p < 0.0001 ) when co-cultured with A549 and 21\% (95\% CI 14.2, 28.1; $\mathrm{p}<0.0001)$ with BEAS-2B cells. Similar findings were seen with the LAD2 mast cell line. Constitutive IL-13 production by $\mathrm{T}_{\mathrm{H}} 2$ cells was reduced from $18000 \pm 1800 \mathrm{pg} / 10^{6}$ cells by $68.6 \%$ (95\% CI 62.0, 75.1; P < 0.0001) by A549 and 59.9\% (95\% CI 53.3, 66.5; $\mathrm{p}<0.0001)$ by BEAS-2B. Epithelial inhibition was similar when cells were separated by a transwell suggesting involvement of a transferable factor.

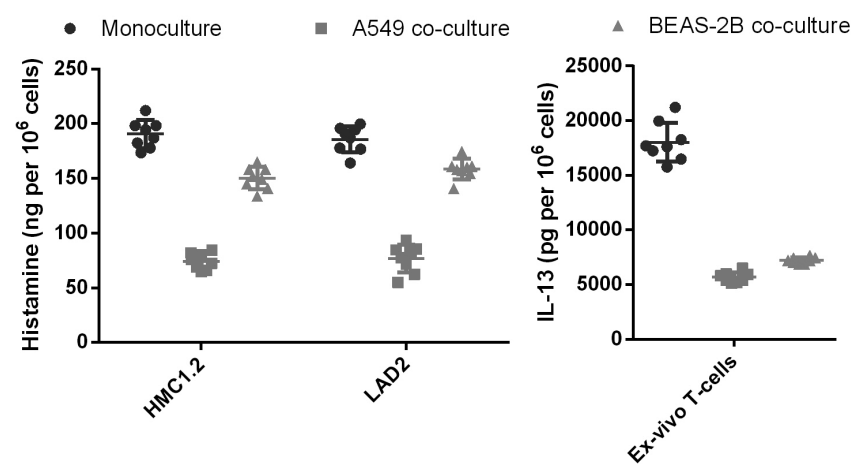

Abstract P103 Figure 1 -hour constitutive histamine (left) and IL-13 (right) release from mast or T-cells in the presence or absence of epithelial cell lines

Conclusion Epithelial cell lines inhibit a range of asthma-related immunological responses, probably by producing an inhibitory substance.

\section{P104 STRUCTURAL AND CELLULAR RELATIONSHIPS IN THE PERIPHERAL LUNG: COMBINING MICRO-CT AND IMMUNOHISTOCHEMISTRY}

JJ Ramsden, JL Norman, PM Lackie, JA Warner. University of Southampton, Southampton, UK

10.1136/thoraxjnl-2015-207770.241

Introduction and objectives The peripheral lung contains a range of structural elements (small airways, blood vessels and lymphatics) together with infiltrating inflammatory cells. These components exist together in complicated spatial arrangements. Lung disease is frequently accompanied by changes in both lung architecture and the number and distribution of inflammatory cells. Light microscopy has been the conventional technique of choice in understanding these changes and relationships but provides only 2-D representations of a complex 3-D network.

We selected to use micro computed tomography $(\mu-\mathrm{CT})$ to image structural elements in the peripheral lung. We aimed to reconstruct the 3-D architecture by combining the $\mu$-CT data with immunohistochemistry (IHC) to positively identify the principal structural elements and inflammatory cells.

Methods Human lung tissue was fixed in formalin, embedded in paraffin wax and subjected to $\mu$-CT scanning. The tissue was then sectioned and immunostained for pancytokeratin (airways), collagen IV (blood vessels), D2-40 (lymphatic vessels) and CD68 (macrophages). The resulting images were used to guide the segmentation of the 3-D $\mu$-CT image stack. IHC, using neurofilament antibodies, was also used on multiple lung samples to attempt to identify nerve fibres in the parenchymal tissue.

Results The main structural elements of the lung periphery could be identified, segmented out and their 3-D architecture examined. Macrophages were found throughout the tissue in large quantities and were most concentrated around the blood vessels and lymphatics. Lymphatic vessels were especially dense in the pleural region and elsewhere were intertwined with blood vessels. Despite being readily identifiable in bronchial samples, nerve fibres were not identified using IHC in the parenchyma.

Conclusions Combining $\mu$-CT and IHC provides a robust method to positively identify important structural elements of the peripheral lung and to localise inflammatory cells in 3-D, thus allowing a detailed review of their spatial relationships. Alternative methodologies may however be advantageous regarding identifying parenchymal nerve fibres for reconstruction. $\mu$ CT and IHC together create a highly accurate 3-D reconstruction but this method remains time consuming; advances in automation and improved tools are required to fully exploit the research potential.

\section{P105 IDENTIFICATION OF 'LARGE' ALVEOLAR MACROPHAGES AND PULMONARY INTRA-VASCULAR MACROPHAGES IN COPD PATIENTS}

AK Ravi, J Plumb, S Mason, G Booth, J Vestbo, SD Singh. The University of Manchester, Manchester Academic Health Science Centre, University Hospital of South Manchester NHS Foundation Trust, NIHR South Manchester Respiratory and Allergy Clinical Research Facility, Manchester, UK

\subsection{6/thoraxjnl-2015-207770.242}

Background A population of small macrophages with increased pro-inflammatory activity has been reported in COPD sputum. We have investigated macrophage size in the alveoli of COPD 
patients using immunofluorescence for the markers CX3CR1 and CD68.

Methods Formalin fixed paraffin embedded tissue blocks were obtained from an area of the lung as far distal to the tumour as possible from COPD patients, smokers (S) and healthy nonsmokers (HNS) undergoing lung resection for lung carcinoma. Sections were labelled with an anti-CX3CR1 antibody and detected using an Alexafluor conjugated secondary antibody. Immunohistochemical detection of CD68 (enzymatic non-biotin amplification technique) confirmed the macrophage phenotype of CX3CR1+ cells.

Results All CX3CR1+ cells expressed CD68. The diameters of COPD macrophages were greater than controls (Table 1). Intravascular CX3CR1+CD68 ${ }^{+}$macrophages were observed in COPD and $\mathrm{S}$ (Table 1).

\begin{tabular}{llll} 
Abstract P105 Table 1 & & & \\
\hline & $\begin{array}{l}\text { COPD } \\
(\mathrm{n}=9)\end{array}$ & $\mathrm{S}(\mathrm{n}=9)$ & HNS $(\mathrm{n}=6)$ \\
& 11.6 & 10.3 & 10 \\
\hline $25^{\text {th }}$ percentile $(\mu \mathrm{m})$ & 13.9 & $12.2^{*}$ & $12.1^{*}$ \\
Median $(\mu \mathrm{m})$ & 16.5 & 14.4 & 13.9 \\
$75^{\text {th }}$ percentile $(\mu \mathrm{m})$ & 15.6 & 22.2 & 0 \\
Vessels with intra-vascular macrophages $(\%)$ & & & \\
\hline
\end{tabular}

The Kruskal-Wallis test with application of Dunn's post-test was used to determine the statistical significance of differences observed in the alveolar macrophage diameter between the three groups. ${ }^{*} p<0.0001$ against COPD.

Conclusion Increased macrophage size in COPD may be linked to altered function. Pulmonary intravascular macrophages have been observed in other mammalian species and may promote pulmonary inflammation through direct release of cytokines into the pulmonary circulation.

\section{P106 TISSUE FACTOR PATHWAY INHIBITOR (TFPI) IS CLEAVED BY MULTIPLE PROTEASES IN COPD LUNGS TO AFFECT CIRCULATING TFPI LEVELS}

B Mallia-Milanes, H Bailey, G Meakin, A Sheehan, A Knox, C Bolton, S Johnson. University of Nottingham, Nottingham, UK

\subsection{6/thoraxjnl-2015-207770.243}

Background Tissue factor pathway inhibitor (TFPI) attenuates intravascular coagulation, a function limited by its proteolysis. Airway inflammation in COPD is associated with protease activity and intravascular thrombotic events, yet the link between proteolysis of TFPI in the airways and intravascular thrombosis in COPD is unexplored.

Aims To explore the presence and processing of TFPI in COPD airways and its relationship to plasma TFPI levels.

Methods COPD sputum and blood were collected at exacerbation and when stable. In vitro cleavage of TFPI was explored by incubation with proteases and Western blotting. TFPI presence and cleavage in sputum was detected by Western blotting. To determine the main protease/s involved in TFPI cleavage, sputum was spiked with recombinant TFPI in the presence of protease inhibitors, followed by Western blotting.

Results TFPI was cleaved in vitro by Matrix Metalloproteinase (MMP)-12, Neutrophil Elastase (NE) and urokinase-type plasminogen activator (uPA) to $<20$.

Conclusion TFPI is cleaved by NE in COPD airways, leading to lower circulating levels. Further studies are needed to determine if lower circulating TFPI levels lead to increased intravascular thrombotic events in COPD.

\section{P107 FUNCTIONAL SIGNIFICANCE OF THE NITRIC OXIDE- ASYMMETRIC DIMETHYLARGININE-DIMETHYLARGININE DIMETHYLAMINOHYDROLASE (NO-ADMA-DDAH) AXIS IN TGF- $\beta$ MEDIATED EPITHELIAL-MESENCHYMAL TRANSITION}

HK Lota, JM Leiper. Nitric Oxide Signalling Group, MRC Clinical Sciences Centre, Imperial College London, London, UK

10.1136/thoraxjnl-2015-207770.244

Background Transforming growth factor (TGF)- $\beta$ is a key mediator of epithelial-mesenchymal transition (EMT), a pathogenetic

\section{1a) iNOS Inhibition: E-cadherin Levels}

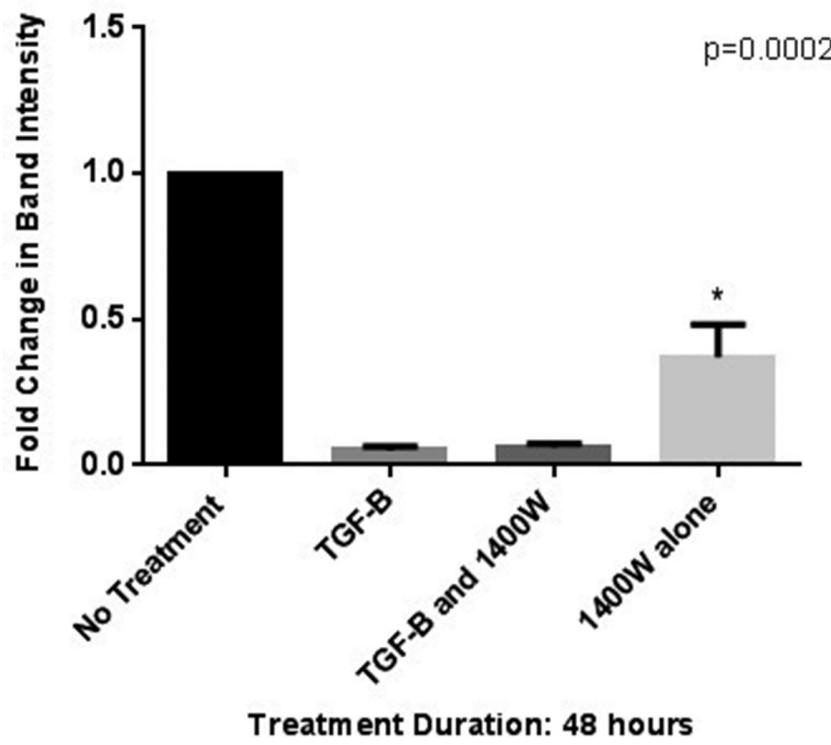

1b) Pan-NOS Inhibition: E-cadherin Levels

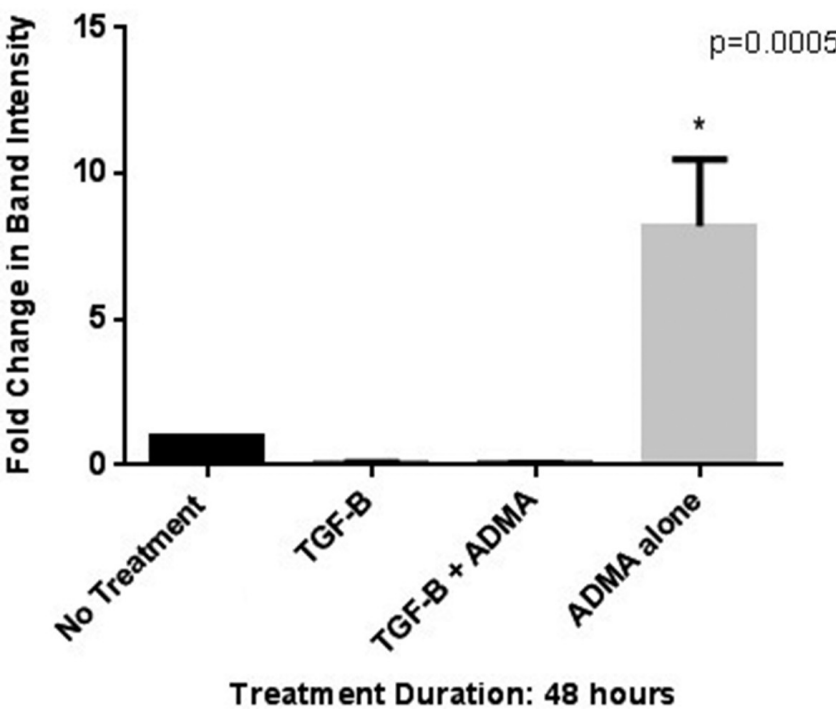

Abstract P107 Figure 1 Fold change in band intensity of E-cadherin levels corrected for tubulin on Wastern blotting: 1a) Treatment with $140 \mathrm{~W}, 1 \mathrm{~b}$ ) Treatment with ADWA ( $p$ values $=0.0002$ and 0.0005 respectively on one-way ANOVA) 